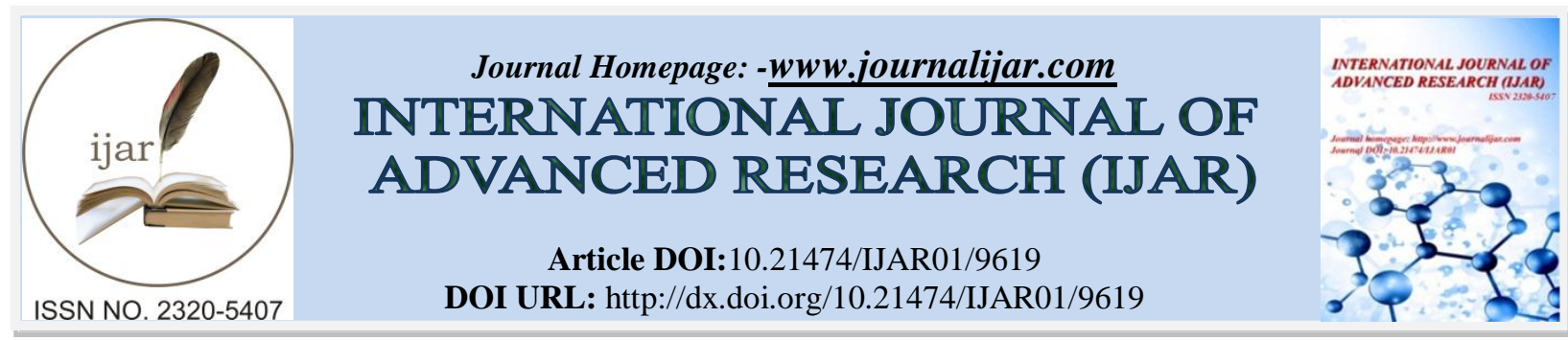

RESEARCH ARTICLE

\title{
PREVALENCE OF POOR SLEEP QUALITY AMONGWOMEN IN GENERAL POPULATIONIN MILITARY AREA , JEDDAH,2018.
}

\section{Faten Althobaiti ${ }^{1}$, Badr Abdulrahman Al Jasir ${ }^{2}$, Jumana Khouja ${ }^{3}$ and Aminah Bargawi ${ }^{4}$.}

1. Resident of community and Preventive Medicine, Jeddah, National Guard Health Affairs.

2. Assistant Professor and Consultant of Community Medicine,Director of Community and Preventive Medicine, Jeddah, National Guard Health Affairs

3. Consultant of Community and Preventive Medicine, Jeddah, National Guard Health Affairs.

4. Coordinator, Community Health Nursing Services, Nursing Continuous Professional Development, Health Informatics and Statistics, PHR-WR, Jeddah,. National Guard Health Affairs.

\section{Manuscript Info}

(..........................

Manuscript History

Received: 20 June 2019

Final Accepted: 22 July 2019

Published: August 2019

\section{Abstract}

Aim:This study aimed to determine sleep quality status among women adult age $\geq 18$ living at National Guard residential city in Jeddah, 2018 .

Method:this was a cross sectional study where a total of 252 women adults were studied. Participants were recruited using multistage sampling. Face to face interview was used to collect data on sociodemographic and Pittsburgh Sleep Quality Index (PSQI) was used to measure sleep quality.

Results: showed that the prevalence of poor sleep quality was $61 \%$. The average sleep latency was 31 minutes ( $S D \pm 27.9), 116(46.1 \%)$ had reported prolonged sleep-onset latency (>30minutes), only 93 (36.9\%) reported that they had less than 7 hours of sleep per night, 101 (40.1\%) had habitual sleep efficiency $(<85 \%)$.

Conclusion:Our study suggests that approximately 2 out of 3 women adults slept poorly and lack of awareness about sleep disorders and the meaning of sleep quality is the major problem of poor sleep quality among the general public.

Copy Right, IJAR, 2019,. All rights reserved.

\section{Introduction:-}

Physical health of the body and its ability to function has many components including exercise, nutrition, weight management,alcohol, drugsand sleep(1). Sleep defined and known as an active, essential and involuntary complicated process, during which essential activities are undertaken inside the body, in combination with a wide variety of other lifestyle behaviors, it was frequently examined as a potential influence of health status (2).

Sleep is a fundamental lifestyle contributor to the health, recognized as a vital part of public health(3), It contains three different components: effectiveness of sleep which includes quality and length of sleep(3)(4).

Quality as a component of sleep effectiveness contains feeling refreshed upon awakening and the total number of hours of sleep obtained while in bed(5)(6), disturbance as being the second component includes interruptions to

Corresponding Author:- Faten Althobaiti.

Address:- Resident of community and Preventive Medicine, Jeddah, National Guard Health Affairs. 
sleep and difficulty falling asleep(4)(7), and supplementation which is the third component refers to augmentation of sleep through napping during the day(4).

Sleep changes have been linked significantly to the health-related quality of life (HRQoL) impairment. They affected multiple aspects of health and well-being and they were associated with obesity, smoking, chronic health conditions, and lower performance among adults(8)(9)(10).

The prevalence of sleep disturbances in the general population ranges from $6 \%$ (clinical diagnosis of insomnia) to $48 \%$ (difficulties in initiating or maintaining sleep or early morning awakening) Poor sleep quality has recently focused on as one of the screening tool of mental health and risk factor of depression in middle-aged and older individuals(11)(12) Intervention to optimize sleep hygiene early in life is becoming a necessity that may prevent cardiovascular disease (13), Alzheimer disease (14), Type 2 Diabetes (15)and reduce the risk of osteopenia and sarcopenia in middle-aged adults (16).

Normal sleep in an adult population characterized by Sleep efficiency $\geq 85 \%$ according to WHO(17), which is the ratio calculated by dividing the time spent in sleep to time spent in bed(18), sleep latency(the time it takes to initiate asleep) <30 minutessleep quantity or duration of seven to nine hours per night for adults, consolidated sleep (uninterrupted sleep by arousals or awakenings)(19), and no daytime dysfunction (daytime sleepiness symptoms while engaging in social activity)(20).

The prevalence of poor sleep quality among women in rural and urban Chinese older adults was $67.2 \%(21)$ and 41.5\%(22), respectively.Furthermore,Among Ethiopian population aged 30 to 70 years inJimma Town, the prevalence of poor sleep quality was $37 \%$ among women(23).

In Saudi Arabia,According to Alsaggaf study that had done among Saudi medical students, the prevalence of the poor sleep quality is present in $30 \%$ of students (24). Another study done by Fatani stated that the prevalence of the EDS is $20.5 \%$ (females $22.2 \%$, males $19.5 \%$ ) (25).

Locally, however, the prevalence data are scarce. Regarding the prevalence in Saudi Arabia, it was estimated in several studies, populations, age groups (students and elderly) and different geographical location but there was no single study done among general society and especially the women. To determine sleep quality status among the female adult age $\geq 18$ living at National Guard residential city in Jeddah,2018.

\section{Methods:-}

\section{Study Area and Period:-}

The study was conducted inNational Guard residential city, which is located in Jeddah, Saudi Arabia. from 1 October to 27 December in 2018. Theresidential city consists of five geographic districts. Each district contains a certain number of villas where they are arranged in an organized cityplanning structure. The total numbers of villas are 1,165 .

A community-based cross-sectional study design was employed on randomly selected households. Sample size (n) was determined using single population proportion formula using $36 \%$ prevalence of poor sleep quality among households based on previous study at 95\% confidence interval and 5\% margin of error. Considering $10 \%$ nonresponse rate, we have premeditated to register 252 participants for final sample size.

Stratified random sampling was used to stratifythe residential city into five major geographical districts, each district contains a certain number of streets (12-15 main roads). After the stratification the systematic random was conducted to allocate to the selected house by selecting every 5th villa starting from thestarting point of the road, the first house was selected by simplerandom sampling of the first five houses.After the study houses were identified, proportional sample was allocated to the selected houses using population proportional to size by using lists of all households (from the existing lists of households from registration records from??) as a sampling frame. Hereby, the participants were selected by simple random sampling technique using lottery method from the sampling frame.Data were collected by 16 data collection trained volunteers ( two-day training was given for 16 data collectors by investigator focusing on the objective of the study, the questionnaire and interview techniques). Data collectors briefed the purpose of the study to the household and requested informed consent to collect data. Data were collected through face-to-face interviews using a structured questionnairefor sociodemographic and other data. 
Checking for completeness and consistency of variables during data collection and before data analysis was continued by investigator.Ethical clearance was obtained from King Abdullah King Abdullah International Medical Research Center's (KAIMRC). The participants were informed and written consent was taken through signature.

To evaluate sleep quality, participants were asked using Pittsburgh Sleep Quality Index (PSQI) to differentiates "poor" from "good" sleep quality by measuring 19 items grouped in seven components: subjective sleep quality, sleep latency, sleep duration, habitual sleep efficiency, sleep disturbances, use of sleeping medications, and daytime dysfunction over the last one month(26). The scores of each statement ranged from $0=$ no difficulty, $1=$ mild difficulty, $2=$ moderate difficulty and $3=$ severe difficulty. The scores of all components are summed up to yield global PSQI scores that ranged from 0 to 21.Global score of 5 and above indicate poor sleep quality while score $<5$ is defined as good sleep quality. Data were edited, coded, and entered and analyzed by IBM SPSS statistics version 25 . During the process of management, descriptive analysis was calculated by mean \pm SD forquantitative data and frequency and proportion for qualitative data and described by tables or figures.

\section{Results:-}

\section{Subject characteristics:-}

A total of 252 female participants who completed the study (Response rate $=95 \%$ ) were included in the analysis. The mean age of participants was $31.2 \pm 11.17$ years ranging from 18 to 72 years, $4 \%$ were postmenopausal. The majority of the participants in our sample were married $56.3 \%$ and housewives or students $77 \%$. only of the participants $23 \%$ were employed. An education level of high school graduation or less was reported by $47.6 \%$ participants, while $52.2 \%$ reported a bachelor's degree or higher. Only $7.5 \%$ were current smokers, and $92.5 \%$ participants were never smokers or former smokers (Table1).

Table1:- Sociodemographic characteristics of the sampled $(n=252)$ women adults in Jeddah,2018.

\begin{tabular}{|l|l|l|}
\hline \multicolumn{2}{|l|}{ Characteristics } & $\mathrm{n}(\%)$ \\
\hline Age (years) & Yes & $31.23 \pm 11.17^{*}$ \\
\hline Menopause & No & $10(4.0)$ \\
& Married Unmarried & $242(96.0)$ \\
\hline Social status & & $142(56.3)$ \\
& High school education or less & $110(43.7)$ \\
\hline Educationalstatus & Bachelor's degree or higher & $120(47.6)$ \\
& Smoker & $132(52.4)$ \\
\hline Smoking status & Non-smoker & $19(7.5)$ \\
& & $233(92.5)$ \\
\hline
\end{tabular}

Sleep quality and its components scores among women adults living at National Guard residential city in Jeddah,2018:-

The minimum global PSQI score was zero and the maximum was 14. The median global PSQI of our sample was 5 (IQR 4,7). A high prevalence of $60.7 \%(\mathrm{n}=153)$ of poor sleep quality was reported. The mean of Sleep latency score was the highest mean among the seven PSQI components which was 1.44, the sleep medication use mean score was the lowest with mean of 0.13 , indicating the rare use of sleep medication among our sample. The mean scores (mean \pm SD) of subjective sleep quality, sleep disturbances, and daytime dysfunction were $(0.69 \pm 0.83),(0.92 \pm 0.45)$, and $(0.86 \pm 0.90)$, respectively (Table2). The average sleep latency was 31 minutes $(\mathrm{SD}=27.9)($ Table2)The average sleep latency was 31 minutes (SD \pm 27.9$)$, and only $93(36.9 \%)$ reported that they had less than 7 hours of sleep per night, $39(15.5 \%)$ had a low habitual sleep efficiency $(<65 \%)$, and $18(7.1 \%)$ used sleep medication within the past one month at the time of interview (Table3)

Table2:-Sleep quality and its components mean scores

\begin{tabular}{|l|l|}
\hline Variables & Mean (SD) \\
\hline PSQI total score & \\
\hline Subjective sleep quality & $5.04 \pm 2.58$ \\
\hline Sleep latency & $0.69 \pm 0.83$ \\
\hline Sleep duration & $1.44 \pm 1.02$ \\
\hline
\end{tabular}




\begin{tabular}{|l|l|}
\hline Habitual sleep efficiency & $0.85 \pm 1.17$ \\
\hline Sleep disturbances & $0.92 \pm 0.45$ \\
\hline Use of sleep medication & $0.13 \pm 0.50$ \\
\hline Daytime dysfunction & $0.86 \pm 0.90$ \\
\hline
\end{tabular}

Table3:-Frequencies of responses to selected questions of the PSQI (in \%).

\begin{tabular}{|c|c|c|c|}
\hline Variables $(n=252)$ & Value & Number & $\%$ \\
\hline \multirow[t]{4}{*}{ Sleep duration } & $>7$ hours & 159 & 63.1 \\
\hline & 6-7 hours & 36 & 14.3 \\
\hline & 5-6 hours & 37 & 14.7 \\
\hline & $<5$ hours & 20 & 7.9 \\
\hline \multirow[t]{4}{*}{ Sleep latency } & No difficulty $(0)$ & 53 & 21.0 \\
\hline & Mild difficulty $(1-2)$ & 83 & 32.9 \\
\hline & Moderate difficulty $(3-4)$ & 67 & 26.6 \\
\hline & Severe difficulty (5-6) & 49 & 19.4 \\
\hline \multirow[t]{4}{*}{ Daytime dysfunction } & No difficulty $(0)$ & 108 & 42.9 \\
\hline & Mild difficulty $(1-2)$ & 85 & 33.7 \\
\hline & Moderate difficulty $(3-4)$ & 45 & 17.9 \\
\hline & Severe difficulty (5-6) & 14 & 5.6 \\
\hline \multirow[t]{4}{*}{ Sleep efficiency } & $>85 \%$ & 151 & 59.9 \\
\hline & $75-84 \%$ & 28 & 11.1 \\
\hline & $65-75 \%$ & 34 & 13.5 \\
\hline & $<65 \%$ & 39 & 15.5 \\
\hline \multirow[t]{4}{*}{ Subjective sleep quality } & Very good & 130 & 51.6 \\
\hline & Fairly good & 78 & 31.0 \\
\hline & Fairly bad & 35 & 13.9 \\
\hline & very bad & 9 & 3.6 \\
\hline \multirow[t]{4}{*}{ Sleep disturbance } & No difficulty $(0)$ & 36 & 14.3 \\
\hline & Mild difficulty (1 to 9) & 199 & 79.0 \\
\hline & Moderate difficulty (>9 to 18 ) & 17 & 6.7 \\
\hline & Severe difficulty $(>18)$ & 0 & 0.0 \\
\hline \multirow[t]{4}{*}{ Use of sleep medication } & Not during the past month & 234 & 92.9 \\
\hline & Less than once a week & 6 & 2.4 \\
\hline & Once or twice a week & 9 & 3.6 \\
\hline & Three or more times a week & 3 & 1.2 \\
\hline \multirow[t]{2}{*}{ Sleep quality score } & Good sleep & 99 & 39.3 \\
\hline & Poor sleep & 153 & 60.7 \\
\hline
\end{tabular}

\section{Discussion:-}

Most of the participants were young who were residing in military area which is known to have unusual age distribution and very dynamic population due to the continuous recruiting and retirement in military section.

The mean PSQI score of our sample was $5.04 \pm 2.58$, high prevalence of poor sleep quality, reaching $60.7 \%$ was found among the participants.

Comparison with other studies in Saudi Arabia was difficult because of their scarcity among the general population. however, As in prior studies, a similar proportion to the results in quite a few studies from different population $(54 \%)$ of female university students reported poor sleep quality at King Faisal University (KFU) in AL-Hasa(27) and $67.9 \%$ among female health care workers in Riyadh city(28) .

This prevalence is consistent with the result of study that have done among Jimma town's adult women population $(61.8 \%)$ while it is much higher than what was found previously among general adults women population in Spain 
(44.6\%) and china (27.0\%) (29),(30). This variation could be either due to the different interview techniquesused to evaluate sleep quality or the different age and race of the study population.

Our participants were more likely to report poor sleep quality may be due to the high unemployed rate, the household chores and caring for children sinceof most of the sample were housewives which could lead to bed time delay,irregular sleep-wake times, inadequate sleep hygiene and sleepfragmentation.(31),(32),(33) .

Consistent with previous studies (34), (35), although the prevalence of poor sleep quality was high among our participants, the majority (82.5\%) reported their sleep quality as fairly good to very good, This discrepancy and findings may be explained by the lack of the awareness regarding the sleep problem, the meaning of sleep quality, sleep hygiene (36) and the long effect of sleep problem on the quality of lifeamong the general population(37), (38).

The self-reported mean of sleep duration was found to be $7.16 \pm 2.01$ hours with median of 7 hours and interquartile range 3. 36.9\% of our participants study reported short sleep duration ( $<7$ hours), which is similar to many other reported studies (41.6\%) (39).one study conducted among adults population in Saudi Arabia showed approximately a third of the population $(33.8 \%)$ had short sleep duration (40).

The average sleep latency of our participants was 31 minutes (SD \pm 27.9 ). prolonged sleep-onset latency (>30minutes)reported among 116(46.1\%)of the participants which is nearly double the prevalence found in studies conducted among medical students in King Khalid University (KKU), Saudi Arabia(22.6\%)(41), male factory workers in Aseer Industrial City, Saudi Arabia(28.5\%)(42) and students at Kyushu University, in Japan (43). less than Saudi medical residents $(68.4 \%)(44)$. prolonged sleep-onset latency has been linked to Depressive Symptoms, mood disturbances and Suicidal Ideation(43), (45).

Furthermore, in the present study, $101(40 \%)$ of our participants study reported poor sleep efficiency $(<85 \%)$ On the other hand,In a study from a sample of the elderly Canadian population, Sophie Desjardins reported that $28.4 \%$ of elderly general population had lower than $80 \%$ sleep efficiency(46). However, a recent systematic review revealed that physical activity increase sleep efficiency in middle-aged and elderly adults, independently of activity type and mode of intensity(47).

The outstanding result of the present study is that daytime symptoms related to insufficient or unrefreshing sleep recognized in more than half $(57.1 \%)$ of our sample participants which is higher than the prevalence reported by sleep health foundation as percentage of daytime dysfunction(30-39\%) among adults worldwide(48).It means every one of two Saudi adult women suffer from insufficient and unrefreshing sleep. Pathological daytime sleepiness usually assessed by the Epworth Sleepiness Scale (ESS).In Saudi Arabia, according to AbdulhamidFatani the prevalence of excessive daytime sleepiness is $22.2 \%$ among adults women(25)while recently, in France study conducted among general population showed that $32.1 \%$ of women have EDS(49).

Most participants $(85.1 \%)$ declared having sleep disturbances.These findings mean four out of five of our participants have sleep disturbances which is higher than what found in a previous study about sleeping habits and disturbances among Saudi adults conducted in Riyadh city(50).

Research to addresses the prevalence of different sleep disorders in the Saudi Arabiaand collaboration among local centerswas recommended by latest review published by King Saud University, and the King Abdulaziz City for Science and Technology about Sleep medicine in Saudi Arabiato demonstrate to health care providers and decision makers the size of the problem(38).

\section{Conclusion:-}

Our study suggests that approximately 2 out of 3 women adults slept poorlyand lack of awareness about sleep disorders and the meaning of sleep quality is the major problem of poor sleep quality among the general public.Furthermore, population-based studies with a larger sample size and a longitudinal follow-up may help to determine the associated factors and potential intervention to improve sleep quality.

Finally, in light of these findings, it is recommended totransform our findings into preventive measure and enhance the awareness of sleep disturbance and educate the public about the modifiable factors such as sleeping habits, hygiene and the effect of short duration, long onset latency on the function, the productivity and the quality of life. 


\section{Strengths and Limitations:-}

The strength of this study is that the data were obtained from general population in military area, at participant's home and by face-to-face interviews rather than a self-reporting.

Our findings are limited by its cross-sectional designand the possibility of recall bias and reporting bias due to using of retrospective measuring questionnaires. the typical issues of generalizability, such that our conclusions would be apply specifically to healthy community-dwelling women adults (the sample was not gender balanced, all of our participants were female).

\section{References:-}

1. Steiner H. Your Health Triangle. 2017;

2. Duncan MJ, Kline CE, Vandelanotte C, Sargent C, Rogers NL, Milia L Di. Cross-Sectional Associations between Multiple Lifestyle Behaviors and Health-Related Quality of Life in the 10, 000 Steps Cohort. 2014;9(4):15 7.

3. Jackson CL. HHS Public Access. 2016;417-40.

4. Ann Call-Schmidt T, Richardson S. Prevalence of Sleep Disturbance and its Relationship to Pain in Adults with Chronic Pain. Vol. 4, Pain management nursing : official journal of the American Society of Pain Management Nurses. 2003. 124-133 p.

5. Gominak SC, Stumpf WE. The world epidemic of sleep disorders is linked to vitamin D deficiency. Med Hypotheses. 2012 Aug;79(2):132-5.

6. Orfeu M. Buxton P. Relationship of sleep deficiency to perceived pain and functional limitations in hospital patient care workers. NIH Public. 2013;54(7):851-8.

7. $\quad$ Cormier RE. Sleep Disturbances. In: Sleep Disturbances R. 1987.

8. Kaleth AS, Edwards ES, Butner KL. Association between sleep disorders, obesity, and exercise : a review. 2013;27-35.

9. Stipelman BA, Mcneel T. The relationship among smoking, sleep, and chronic rheumatic conditions commonly associated with pain in the national health interview survey Brooke. NIH. 2014;36(5):1-18.

10. Riaz N, Wolden SL, Gelblum DY, Eric J. Trouble Sleeping Associated with Lower Work Performance and Greater Healthcare Costs: Longitudinal Data from Kansas State Employee Wellness Program. Heal Hum sevices. 2016;118(24):6072-8.

11. Guo J, Liu C, Wang X, Qu Z, Zhang W, Zhang X. Relationships between depression, pain and sleep quality with doctor visits among community-based adults in north-west China. Public Health. 2017 Jun;147:30-8.

12. Bhandari PM, Neupane D, Rijal S, Thapa K, Mishra SR, Poudyal AK. Sleep quality, internet addiction and depressive symptoms among undergraduate students in Nepal. BMC Psychiatry. 2017 Mar;17(1):106.

13. Narang I, Manlhiot C, Davies-Shaw J, Gibson D, Chahal N, Stearne K, et al. Sleep disturbance and cardiovascular risk in adolescents. CMAJ. 2012 Nov;184(17):E913-20.

14. Sprecher KE, Koscik RL, Carlsson CM, Zetterberg H, Blennow K, Okonkwo OC, et al. Poor sleep is associated with CSF biomarkers of amyloid pathology in cognitively normal adults. Neurology. 2017 Aug;89(5):445-53.

15. Lee JA, Sunwoo S, Kim YS, Yu BY, Park HK, Jeon TH, et al. The Effect of Sleep Quality on the Development of Type 2 Diabetes in Primary Care Patients. J Korean Med Sci. 2016 Feb;31(2):240-6.

16. Lucassen EA, de Mutsert R, le Cessie S, Appelman-Dijkstra NM, Rosendaal FR, van Heemst D, et al. Poor sleep quality and later sleep timing are risk factors for osteopenia and sarcopenia in middle-aged men and women: The NEO study. PLoS One. 2017;12(5):e0176685.

17. Germany B. WHO technical meeting on sleep and health European Centre for Environment and Health. 2004;(January):22-4.

18. Outline C, Objectives L, Terms KEY. Normal Sleep. 1-11 p.

19. Ramar K, Olson EJ. Management of Common Sleep Disorders. 2013;

20. Okubo N, Matsuzaka M, Takahashi I, Sawada K, Sato S, Akimoto N, et al. Relationship between self-reported sleep quality and metabolic syndrome in general population. Vol. 14, BMC public health. 2014. 562 p.

21. Wang P, Song L, Wang K, Han X, Cong L, Wang Y, et al. Prevalence and associated factors of poor sleep quality among Chinese older adults living in a rural area: a population-based study. Aging Clin Exp Res [Internet]. 2019;0(0):0. Available from: http://dx.doi.org/10.1007/s40520-019-01171-0

22. Luo J, Zhu G, Zhao Q, Guo Q, Meng H, Hong Z, et al. Prevalence and Risk Factors of Poor Sleep Quality among Chinese Elderly in an Urban Community: Results from the Shanghai Aging Study. 2013;8(11):1-7.

23. Berhanu H, Mossie A, Tadesse S, Geleta D. Prevalence and Associated Factors of Sleep Quality among Adults in Jimma Town, Southwest Ethiopia : A Community-Based Cross-Sectional Study. 2018;2018.

24. Alsaggaf MA, Wali SO, Merdad RA, Merdad LA. Sleep quantity, quality, and insomnia symptoms of medical 
students during clinical years. 2016;37(2):173-82.

25. Fatani A, Al-Rouqi K, Al Towairky J, Ahmed AE, Al-Jahdali S, Ali Y, et al. Effect of age and gender in the prevalence of excessive daytime sleepiness among a sample of the Saudi population. J Epidemiol Glob Health. 2015 Dec;5(4 Suppl 1):S59-66.

26. Buysse DJ, Reynolds CF 3rd, Monk TH, Berman SR, Kupfer DJ. The Pittsburgh Sleep Quality Index: a new instrument for psychiatric practice and research. Psychiatry Res. 1989 May;28(2):193-213.

27. AL-Otaibi HH. Associations between Sleep Quality and Different Measures of Obesity in Saudi Adults. Glob J Health Sci. 2016;9(1):1.

28. Ajmi M. Sleep quality among residents of Saudi Board of Family Medicine compared to service physicians in primary care centers. Int J Med Sci Public Heal. 2015;4(7):982.

29. Madrid-Valero JJ, Martinez-Selva JM, Ribeiro do Couto B, Sanchez-Romera JF, Ordonana JR. Age and gender effects on the prevalence of poor sleep quality in the adult population. Gac Sanit. 2017 Jan;31(1):18-22.

30. Tang J, Liao Y, Kelly BC, Xie L, Xiang YT, Qi C, et al. Gender and Regional Differences in Sleep Quality and Insomnia: A General Population-based Study in Hunan Province of China. Sci Rep [Internet]. 2017;7(March):1-9. Available from: http://dx.doi.org/10.1038/srep43690

31. Sarıarslan HA, Gulhan YB, Unalan D, Basturk M, Delibas S. The relationship of sleep problems to life quality and depression. Neurosciences. 2015;20(3):236-42.

32. Lisa J. Meltzer. Sleep in the Family. NIH. 2012;58(3):765-74.

33. Nancy Foldvary-Schaefer, DO M. Sleep Disorders. November 2012. p. 8.

34. Almojali A, A. Almalki S, S. Alothman A, Masuadi E, K. Alaqeel M. The prevalence and association of stress with sleep quality among medical students. Vol. 7, Journal of Epidemiology and Global Health. 2017.

35. MUSA NA, MOY FM, WONG LP. Prevalence and factors associated with poor sleep quality among secondary school teachers in a developing country. Ind Health. 2018;56(5):407-18.

36. Yazdi Z, Loukzadeh Z, Moghaddam P, Jalilolghadr S. Sleep Hygiene Practices and Their Relation to Sleep Quality in Medical Students of Qazvin University of Medical Sciences. Vol. 5, Journal of Caring Sciences. 2016. $153-160 \mathrm{p}$.

37. Strine TW, Chapman DP. Associations of frequent sleep insufficiency with health-related quality of life and health behaviors. Sleep Med. 2005 Jan;6(1):23-7.

38. Bahammam A. Sleep medicine in Saudi Arabia: Current problems and future challenges. Vol. 6, Annals of thoracic medicine. 2011. 3-10 p.

39. Tuomilehto H, Peltonen M, Partinen M, Seppa J, Saaristo T, Korpi-Hyovalti E, et al. Sleep duration is associated with an increased risk for the prevalence of type 2 diabetes in middle-aged women - The FIN-D2D survey. Sleep Med. 2008 Mar;9(3):221-7.

40. Ahmed AE, Al-jahdali F, Alalwan A, Abuabat F. Prevalence of sleep duration among Saudi adults. 2017;38(3):276-83.

41. S AF, Al- H. Sleep Patterns and Predictors of Poor Sleep Quality among Medical Students in King Khalid University, Saudi Arabia. 2016;23(3):94-102.

42. Almetrek MAS. Effect of Shift-Work on Sleeping Quality of Male Factory Workers in Saudi Arabia. 2014;4(1).

43. Supartini A, Honda T, Basri NA, Haeuchi Y, Chen S, Ichimiya A, et al. The Impact of Sleep Timing, Sleep Duration, and Sleep Quality on Depressive Symptoms and Suicidal Ideation amongst Japanese Freshmen : The EQUSITE Study. 2016;2016.

44. Alsaif HI. Prevalence of and risk factors for poor sleep quality among residents in training in KSA. J Taibah Univ Med Sci [Internet]. 2019;14(1):52-9. Available from: https://doi.org/10.1016/j.jtumed.2018.11.007

45. Report T. Insuf fi cient Sleep in Adolescents and Young Adults: An Update on Causes and Consequences. 2014;134(3).

46. Ac c ep te d us cr ip t Ac c d us cr t. 2019;1-39.

47. Dolezal BA, Neufeld E V, Boland DM, Martin JL, Cooper CB. Interrelationship between Sleep and Exercise : A Systematic Review. 2017;2017.

48. Adams R, Appleton S, Taylor A, Antic N. Report to the Sleep Health Foundation 2016 Sleep Health Survey of Australian Adults The Adelaide Institute for Sleep Health. 2016;

49. Jaussent I, Morin CM, Ivers H, Dauvilliers Y. Incidence, worsening and risk factors of daytime sleepiness in a population-based 5-year longitudinal study. Sci Rep [Internet]. 2017;(December 2016):1-11. Available from: http://dx.doi.org/10.1038/s41598-017-01547-0

50. Al-tannir MA, Kobrosly SY, Al-badr AH, Salloum NA. Characterizing sleeping habits and disturbances among. 2016;37(12):1372-80. 